not be commercially justifiable. A further pressure comes from doctors in the abortion business. who have consistently opposed the pill; for them, abortion services provide a cash income that would be hard to replace. There may well turn out to be a temptation to leave matters as they stand. to the detriment of those taking a high-dose pill.

Alun Anderson

\section{Planetary science}

\section{NASA decision causes dismay}

\section{Washington}

THE decision of the National Aeronautics and Space Administration (NASA) to abandon the Comet Rendezvous and Asteroid Flyby (CRAF) mission as a candidate for a new start in fiscal year 1987 has caused dismay to planetary scientists on both sides of the Atlantic. The mission was to have been the first using the Mariner Mark II Spacecraft, now under development, and there is concern both about the budgetary implications for planetary science and about planning of future missions that may benefit from information provided by CRAF.

NASA's decision resulted from budgetary pressures; the two new starts it has requested for fiscal year 1987 are TOPEX, an oceanographic satellite, and the first part of the US contribution to the International Solar Terrestrial Physics Program. Starting planning for CRAF in 1987 would have meant the agency could look forward to a launch in 1992. The enforced delay makes it likely that a group of engineers working on the Galileo Jupiter spacecraft, now nearing completion, will have to be disbanded rather than moved straight to CRAF, and has shaken the faith of those who expected NASA to continue supporting planetary science to the tune of about $\$ 300$ million a year.

The delay is also likely to impede planning of future missions that might involve collaboration between NASA and the European Space Agency (ESA). ESA is thinking about a sample/return mission to a "primordial body" (asteroid or comet) some time in the next decade that might use CRAF data, and there has been talk about plans for NASA/ESA collaboration on a mission to Saturn, called Cassini, that would, like CRAF, have been based on the Mariner Mark II craft. West Germany is expecting to fly scientific instruments and provide a propulsion module for CRAF, and the decision has caused "great disappointment" there according to one researcher. Dr J. Kissel of the Max Planck institute for nuclear physics said West German scientists would have valued more time to prepare their instrument proposals if the mission is to be delayed on NASA's account; as things stand, NASA is expecting formal proposals before the end of this month.

Tim Beardsley

British astronomy

\title{
Lockyer observatory to be sold
}

THE future of a trust established by $\mathrm{Sir}$ Norman Lockyer, the editor of Nature from the foundation of the journal in 1869 until his retirement after exactly 50 years. for the benefit of British astronomy is now in doubt. The council of the Norman Lockyer Corporation, the company limited by guarantee which for the time being owns the 44-acre site at Sidmouth, in East Devon, on which Norman Lockyer's observatory is situated, is on the point of selling the largely decrepit collection of telescope domes and buildings to the East Devon District Council for $£ 140,000$.

An attempt by Mr Norman Walker, an astronomer at the Royal Greenwich Observatory (RGO), to rescue the Sidmouth site is meanwhile in limbo. $\mathrm{Mr}$ Walker has been negotiating with the executive council of the Norman Lockyer Corporation, and latterly with the putative owners, the East Devon council, on a plan to refurbish one of the telescopes and to install a 100 -inch reflector in another of the three telescope domes. Mr Walker says that if he could lease the site from one or other of its owners at a reasonable price, he would give up his job, move to Sidmouth and hope to pay for the cost of maintaining the essential buildings on the site by the income from an estimated 50,000 visitors a year to an exhibition he would mount.

Mr Walker's scheme is only the latest in a series of attempts to rescue the Sidmouth scheme in the past two decades, since the Norman Lockyer Corporation formed a loose association with the University of Exeter (then the University College of the South-West) in the heady days of the expansion of the British university system. As things are, there are no funds (and no ambitions) to support a programme of observational astronomy at Exeter, while the cost of keeping the site in some state of order is beyond the resources of the university. A scheme for turning the Sidmouth site into an educational centre for East Devon schools, canvassed a decade ago, similarly came to nothing.

According to $\mathrm{Mr}$ M. J. Hislop, the registrar of the University of Exeter who is secretary of the Norman Lockyer Corporation, negotiations with the East Devon council have been under way for longer than the two years during which $\mathrm{Mr}$ Walker's proposals have been put forward. The proposed selling price for the Sidmouth site is apparently that recommended by the district valuer, a person whose statutory duty is to value property for property taxation purposes. Mr Hislop says that the site is covered by restrictions on development which reduce its value.

Nevertheless, $\mathrm{Mr}$ Walker says he is offended that the proposals put to him by the subcommittee appointed by the East
Devon council to look after the proposed purchase are unacceptable. Apparently he has been offered a lease on the part of the site occupied by the three domes and the three other buildings (a workshop, a set of offices and a bungalow) for $£ 47,0(0)$, with a nominal rent for the first few of 90 years, but with the provision that he would not be able to transfer the lease to the handful of colleagues who he hopes will join in the planned flight from RGO to what he hopes will be one of the few remaining sites for observational astronomy in Rritain.

The corporation's view of the future, according to Mr Hislop, is that the sale to the local council will now almost certainly go ahead, although a decision to dispose of the only substantial asset of the charitable trust would have to be agreed by a meeting of the whole corporation, which appears not yet to have been arranged. Whether Mr Walker can back his plans with firm undertakings of financial support before that meeting is an open question.

One curious feature of these developments is that Lockyer seems to have been over-exact in his design of his charitable trust, whose objects are said to be "to build and maintain observatories for the good of astronomy". The result will be that if the proposed sale goes ahead, the corporation will either have to find some other cognate project on which to spend $£ 140,000$ or arrange that the terms of the trust are changed.

Mr Hislop says that while the membership of the corporation includes some who were members in Lockyer's time, it now also includes many who have joined to "find out what is going on".

\section{Weizmann Institute}

\section{Rehovot}

IMMUNOLOGIST Michael Sela, president of the Weizmann Institute for the past ten years, will step down at the end of the month to be replaced by mathematician Aryeh Dvoretzky, now head of the Institute of Advanced Study at the Hebrew University. Sela plans to return to full-time research.

Sela is proudest of his programme of career development chairs, usually endowed by specific donors, by means of which 60 younger scientists have so far benefited. Building work has been given low priority, chiefly because of declining support from the government of Israel.

Best known for his work in synthetic antigens, Sela intends to use a sabbatical year in the United States to develop his interests in synthetic vaccines, multiple sclerosis and the immunological targeting of drugs. 